L. Pico MD, *

S. Hernot $\mathrm{MD},{ }^{*}$

I. Nègre MD, *

K. Samii MD PhD, *

D. Fletcher MD PhD $\dagger$

\title{
Peroperative titration of morphine improves immediate postoperative analgesia after total hip arthroplasty
}

Purpose: To determine the Influence of peroperative titrated morphine on postoperative pain control.

Methods: Forty patients received general anesthesia for total hip arthroplasty (THA) and were divided into two groups of 20. In the Peroperative group (Perop group;) morphine was titrated at the end of surgery ( 3 mg iv every 5 or $10 \mathrm{~min}$ ) in spontaneously breathing intubated patients, until the respiratory rate (RR) decreased. No morphine was administered to Postop group. In the Post Anesthesia Care Unit (PACU) patients in Perop and Postop groups received morphine until adequate pain relief VAS $\leq 30 \mathrm{~mm}$. Patients used patient-controlled analgesia (PCA) for the next $24 \mathrm{hr}$. In the PACU, the delay for analgesia, doses of morphine used and incidence of side effects were recorded.

Results: In the Perop group, patients received $10.3 \pm 1.3 \mathrm{mg}(2-20 \mathrm{mg})$ as peroperative titration and had achieved adequate analgesia more rapidly than in the Postop group (42 \pm 7 min vs $76 \pm 7$ min ); $P=0.0026$ ). Analgesia in the PACU in the Postop group required larger doses of morphine ( $15.4 \pm 1.5 \mathrm{mg}$;) than in the Perop group $(7.3 \pm 1.3 \mathrm{mg} ; P=0.0004)$. The respiratory rate decrease during peroperative morphine titration was correlated to the morphine dose needed in the PACU $(P=0.035)$. Respiratory depression in the PACU was more common in the Postop group than in the Perop group (five patients vs no patient $P=0.017$ ).

Conclusion: This study demonstrated that the peroperative administration of morphine can facilitate immediate postoperative pain management.

Objectif : Intérêt d'un titrage de la morphine peropératoire pour l'analgésie postopératoire.

Méthode : Quarante patients opérés pour une prothèse totale de hanche sous anesthésie générale ont été inclus. Dans le groupe Perop $(n=20)$ la morphine a été titrée, en intraveineux, à la fin de l'intervention (3 mg toutes les 5 ou 10 min) chez des patients intubés, respirant spontanément jusqu'à diminution de la fréquence respiratoire (FR). Aucune administration de morphine peropératoire n'a été faite chez les patients du groupe Postop $(n=20)$. A la salle de réveil, les patients des deux groupes recevaient de la morphine titrée jusqu'à analgésie efficace définie par un score EVA $=30 \mathrm{~mm}$. Les patients utilisaient ensuite une analgésie autocontrôlée pendant $24 \mathrm{~h}$. Les délais d'analgésie, les doses de morphine nécessaires et les effets secondaires étaient évalués en salle de réveil.

Résultats : Les caractéristiques des patients et de l'intervention chirurgicale sont similaires dans les deux groupes. Dans le groupe Perop les patients reçoivent 10,3 \pm 1,3 mg (2-20 mg) de morphine peropératoire. Les patients du groupe Perop ont une analgésie efficace plus rapidement (42 \pm 7 min (0-95 min) vs $76 \pm 7$ min (35- I 50 min) que ceux du groupe Postop; $P=0,0026)$. L'analgésie efficace est obtenue avec plus de morphine dans la salle de réveil pour le groupe Postop (I 5,4 \pm I,5 mg; 9-29 mg) que pour le groupe Perop (7,3 \pm I,3 mg (3-28 mg); P $=0,0004)$. L'importance du ralentissement de la FR durant le titrage de morphine peropératoire est en corrélation avec la diminution des besoins en morphine à la salle de réveil $(P=0.035)$. La dépression respiratoire en salle de réveil est plus fréquente dans le groupe Postop (5 patients vs 0 patient dans le group Perop; $P=0,0$ । 7 ).

Conclusion : La morphine peropératoire titrée facilite l'analgésie postopératoire immédiate.

From the Département d'Anesthésie Réanimation, ${ }^{*}$ Hôpital Bicêtre, Bicêtre and Département d'Anesthésie Réanimation,† Hôpital Raymond Poincaré, Garches, France.

Address correspondence to: Dr. Dominique Fletcher, Département d'Anesthésie Réanimation, Hôpital Raymond Poincaré, 104 boulevard Raymond, Poincaré 92380, Garches, France. Phone: 33-1-47107622; Fax: 33-1-47107623; E-mail: dar.garches@rpc.ap-hop-paris.fr Accepted for publication December 22, 1999 


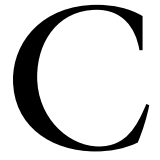

ONTROL of pain is important in the immediate postoperative period. The transition between anesthesia and adequate analgesia in awake patients is sometimes difficult to manage. Problems encountered include patient evaluation in the immediate postoperative period, delay in obtaining analgesia and the necessity to adapt the treatment to individual variability. One possibility is to start administering analgesics before the end of surgery using non opioid analgesics and/or morphine. Although this anticipation of analgesia is widely used, few studies have evaluated morphine administration in the anesthetized patient at the end of surgery to facilitate immediate postoperative analgesia. ${ }^{1-4}$ These studies, using mostly remifentanil as peroperative opioid, ${ }^{1-3}$ all used a single bolus of morphine $\left(0.15-0.25 \mathrm{mg} \cdot \mathrm{kg}^{-1}\right) \quad 20-30 \mathrm{~min}$ before the end of surgery. This single bolus technique seems to have been responsible for postoperative respiratory depression when the highest dose was used $\left(0.25 \mathrm{mg} \cdot \mathrm{kg}^{-1}\right) .^{2}$ Titration using repeated boluses of morphine is the best technique to relieve intense postoperative pain rapidly and to adapt the doses to the interindividual variability. ${ }^{5}$ The technique is frequently used in the Post Anesthesia Care Unit. This approach may be used during emergence from anesthesia, ${ }^{6}$ but no study has evaluated its feasibility. To standardize peroperative titrated morphine administration in spontaneously breathing unconscious patients, the most sensitive clinical criterion of adequate opioid analgesia may be the respiratory rate (RR). Therefore, the purpose of this study was - first to evaluate the influence of peroperative administration of titrated morphine on the quality of postoperative pain control in a controlled randomized double blind study and secondly, to define whether the RR of awakening patients may be an adequate criterion with which to control this titration.

Material and methods

Patient selection and randomization procedure

Following Institutional Ethics Committee approval and written informed consent, 43 adults (ASA physical status 1-3) scheduled for total hip arthroplasty (THA) were randomly assigned to one of two groups and prospectively studied using a double-blind design. Non inclusion criteria were: age $<18 \mathrm{yr}$ or $>85 \mathrm{yr}$, ASA physical status $>3$, any type of surgery other than THA, surgery performed under regional anesthesia or combination of general anesthesia and regional anesthesia.

The patients were excluded in the case of prescription of other analgesics drugs than the morphine in the operating room or the PACU. They were randomly allocated to two groups using a random num- ber table: Peroperative morphine (Perop group) with peroperative titration of morphine and Postoperative morphine group (Postop group) with no peroperative titration of morphine.

Anesthesia and peroperative administration of morphine All patients received $2 \mathrm{mg} \cdot \mathrm{kg}^{-1}$ hydroxyzine $120 \mathrm{~min}$ before surgery. General anesthesia was induced with $3-5 \mathrm{mg} \cdot \mathrm{kg} \cdot{ }^{1}$ thiopental, $0.1 \mathrm{mg} \cdot \mathrm{kg}^{-1}$ pancuronium or 1-1.5 mg. $\mathrm{kg}^{-1}$ succinylcholine and $1.5 \mu \mathrm{g} \cdot \mathrm{kg}^{-1}$ fentanyl. The trachea was intubated and anesthesia was maintained with $\mathrm{O}_{2} / \mathrm{N}_{2} \mathrm{O}$ and isoflurane. Reinjection of fentanyl was allowed at the discretion of the anesthesiologist responsible for the case, with the last injection of opioid $30 \mathrm{~min}$ before the presumed end of surgery (i.e. at the end of skin closure).

The peroperative morphine group (Perop group) received peroperative morphine titration administered while muscle and skin closure was performed with patients emerging from anesthesia and spontaneously breathing via an orotracheal tube. After discontinuation of isoflurane and neuromuscular reversal when necessary as determined by train-of-four stimulation, boluses of morphine were administered according to two protocols in alternate patients in the Perop group: $3 \mathrm{mg}$ every five minutes and $3 \mathrm{mg}$ every $10 \mathrm{~min}$. The titration was continued until the respiratory rate $(\mathrm{RR})$ decreased with a lowest RR of 12 breaths $\mathrm{min}^{-1}$ (bpm). During this titration the $\mathrm{P}_{\mathrm{ET}} \mathrm{CO}_{2}$, tidal volume and the isoflurane $_{\mathrm{ET}}$ concentration were monitored.

\section{Postoperative pain management and evaluation}

Personnel involved in patient management and data collection in the PACU were unaware of the group to which the patient had been assigned. In case of emergency the anesthesiologist responsible for the patient in the PACU had access to the patient allocation. After arrival in the Post Anesthesia Care Unit (PACU), when the patients were completely awake (i.e. sedation score $\leq 2)$ and capable of using the visual analog scale (VAS), pain was controlled by titration of intravenous morphine administered by a nurse. A $10-\mathrm{cm}$ VAS (with endpoints labeled "no pain" and "worst possible pain") was used to assess pain intensity at rest. The sedation was monitored using the following scale: 0 - patient fully alert; 1 - patient with intermittent sedation; 2 - patient sedated but responsive to verbal stimuli; 3 - patient unresponsive to verbal stimuli. All patients received 3-5 $1 \cdot \mathrm{min}^{-1}$ supplemental oxygen in the PACU. Morphine titration in the PACU consisted of repeated boluses of $3 \mathrm{mg}$ morphine every $10 \mathrm{~min}(2$ $\mathrm{mg}$ every $10 \mathrm{~min}>65 \mathrm{yr}$ ) until the pain score was reported as $\leq 30 \mathrm{~mm}$ on a visual analog scale by the 
patient. Side effects (nausea, vomiting, pruritus, urinary retention) were recorded if present. Respiratory depression was defined in the PACU as the combination of sedation (sedation score $\geq 2$ ) and hypoxemia with a $\mathrm{SpO}_{2}<95$ or the combination of a sedation score $\geq 2$ and a respiratory rate $\leq 10 \mathrm{bpm}$.

The titration was stopped in case of a sedation score $=3$ or respiratory depression (i.e. sedation score $\geq 2$ and $\mathrm{RR} \leq 10 \mathrm{bpm}$ ). The titration was also interrupted when the VAS pain score remained $\geq 50 \mathrm{~mm}$ for $>60$ min after the start of morphine administration. In case of inadequate analgesia, the anesthesiologist responsible for the patient could administer a non opioid analgesic drug as propacetamol (Pro-Dafalgan ${ }^{\mathrm{TM}}$ a prodrug of acetaminophen UPSA laboratory Rueil Malmaison France) or ketoprofen (Profenid ${ }^{\mathrm{TM}}$ Specia Laboratory Rueil Malmaison France).

Delay in adequate pain control was defined as the interval between the time of arrival in the PACU and the first visual analog pain score $\leq 30$. In case of failure of postoperative titration due to sedation, respiratory depression or persistent high pain score $>60 \mathrm{~min}$, duration of morphine titration was considered as the delay for pain control.

Subsequently, patients were given access to a patientcontrolled analgesia (PCA) pump (PCA II Bard). The pump was set to deliver a $1 \mathrm{mg}$ bolus of morphine $i v$, a lock-out time of eight minutes and a maximum cumulative dose of $24 \mathrm{mg}$ every four hours without a continuous infusion. This regimen of PCA was continued for $24 \mathrm{hr}$ on the surgical ward, during which time other analgesics were administered when necessary.

TABLE I Patients demographics and anesthetic procedure

\begin{tabular}{|c|c|c|c|}
\hline & $\begin{array}{l}\text { Perop group } \\
(n=20)\end{array}$ & $\begin{array}{l}\text { Postop group } \\
(n=20)\end{array}$ & $P$ \\
\hline Age (yr) & $\begin{array}{l}57.5 \pm 3.3 \\
30-79)\end{array}$ & $\begin{array}{l}59.3 \pm 3 \\
(28-81)\end{array}$ & 0.83 \\
\hline Weight (kg) & $\begin{array}{l}74.2 \pm 3.3 \\
(49-98)\end{array}$ & $\begin{array}{l}71.2 \pm 3 \\
(52-98)\end{array}$ & 0.46 \\
\hline Sex male $(n)$ & 9 & 11 & 0.53 \\
\hline Peroperative fentanyl $(\mu \mathrm{g})$ & $\begin{array}{l}307 \pm 25 \\
(100-550)\end{array}$ & $\begin{array}{l}312 \pm 24 \\
(150-500)\end{array}$ & 0.88 \\
\hline Duration of surgery (min) & $\begin{array}{l}138 \pm 5 \\
(120-165)\end{array}$ & $\begin{array}{l}140 \pm 11 \\
(100-300)\end{array}$ & 0.30 \\
\hline $\begin{array}{l}\text { Delay: last injection of } \\
\text { fentanyl-postop } \\
\text { titration ( } \mathrm{min})\end{array}$ & $\begin{array}{l}132 \pm 9 \\
(35-195)\end{array}$ & $\begin{array}{l}117 \pm 10 \\
(30-220)\end{array}$ & 0.18 \\
\hline
\end{tabular}

Values are expressed as mean \pm SEM (range) or number of patients (n)

Perop group: patients who received morphine at the end of surgery; Postop group: patients who did not receive morphine at the end of surgery but usual titration in the Post Anesthesia Care Unit.
The difficulty of pain control was evaluated at PACU discharge with a verbal scale by the nurses (very easy; easy; rather difficult; difficult; very difficult). The patients also evaluated pain control (inadequate; reasonable; good; perfect) and side effects (none, present not disturbing, disturbing, very disturbing). The Aldrete score criteria were used to define when the patient may be discharged from the PACU.

\section{Data analysis}

The Mann Whitney U test was used to compare continuous variables. Regression analysis was used to evaluate the relation between peroperative titration and the quality of postoperative analgesia. Chi square test was used to compare frequency of side effects and sex distribution. A value of $P<0.05$ was considered significant. Data are expressed as mean \pm SEM (range).

\section{Results}

\section{Demographics and clinical variables}

Three patients were excluded from the study: two in the Perop group due to peroperative administration of additional analgesics, one in the Postop group due to a regional anesthesia combined with general anesthesia. Demographic and clinical variables for the two groups are presented in Table I. There was no difference between the groups in sex, age, weight, duration of surgery, and the cumulative peroperative dose of fentanyl. The delay between the last administration of peroperative fentanyl and the postoperative morphine titration was similar in both groups.

\section{Peroperative titration (Figure)}

The two protocols of peroperative morphine administration produced similar results (data not shown) and therefore the results were analyzed globally. The patients of the Perop group received a peroperative titration of $10.3 \pm 1.3 \mathrm{mg}(2-20 \mathrm{mg})$ of morphine over $25.5 \pm 3 \mathrm{~min}(10-55 \mathrm{~min})$. At the beginning of the peroperative titration, the patient respiratory rate (RR) was $19.6 \pm 1 \mathrm{bpm}(8-28 \mathrm{bpm})$, the tidal volume was $291 \pm 36 \mathrm{ml}(100-500 \mathrm{ml})$, the $\mathrm{P}_{\mathrm{ET}} \mathrm{CO}_{2}$ was $(41.5$ $\pm 1.7 \mathrm{mmHg})(30-56 \mathrm{mmHg})$ and the isoflurane $\mathrm{ET}_{\mathrm{T}}$ concentration was $0.4 \pm 0.05 \%(0-0.9 \%)$. At the end of the peroperative titration the RR was $13.7 \pm 1 \mathrm{bpm}$ $(10-23 \mathrm{bpm})$, the tidal volume $375 \pm 125 \mathrm{ml}(200$ $600 \mathrm{ml})$, the $\mathrm{P}_{\mathrm{ET}} \mathrm{CO}_{2}$ was $44.2 \pm 2 \mathrm{mmHg}(44.2 \pm 1.7$ $\mathrm{mmHg})(30-61 \mathrm{mmHg})$ and the Et isoflurane concentration was $0.13 \pm 0.04 \%(0-0.75 \%)$. Only 11 patients reached the lowest RR of $12 \mathrm{bpm}$. Among the nine patients who did not reach a RR of $12 \mathrm{bpm}$, the trachea was extubated in five due to total awakening, and in four the peroperative titration was discontinued 


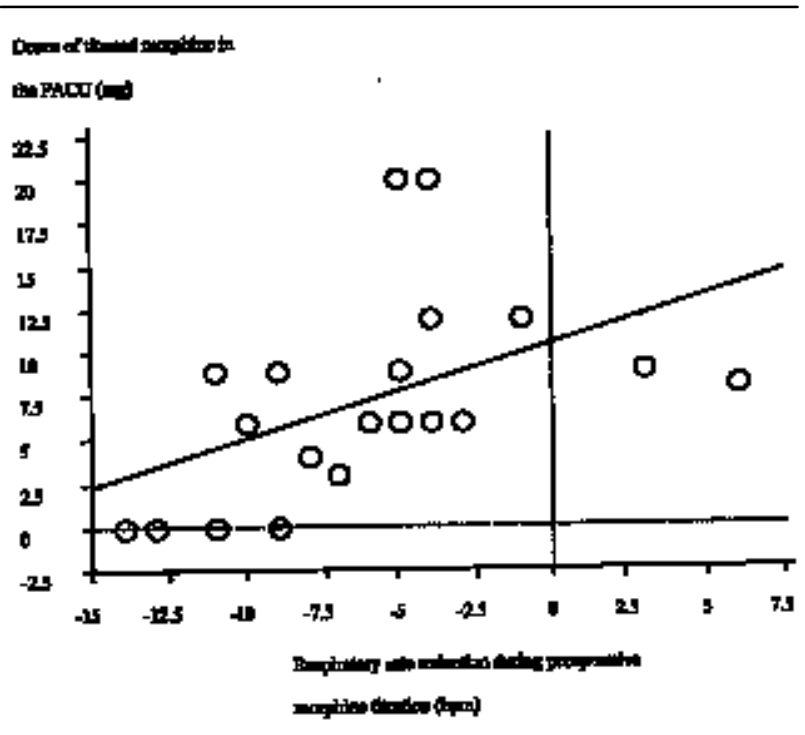

FIGURE Relation between the reduction of respiratory rate (RR) during peroperative titration (bpm) and the dose of titrated morphine in the PACU $(\mathrm{mg})$. The morphine dose in the PACU is correlated to the $\mathrm{RR}$ decrease during peroperative titration $(\mathrm{R}=$ 0,$24 ; P=0.035$ ).

because the RR did not further decrease after $30 \mathrm{~min}$ Patients reaching a $\mathrm{RR}$ of 12 bpmneeded less morphine in the PACU $(4.7 \pm 1.3 \mathrm{mg} v s 10.3 \pm 2 \mathrm{mg}$ for other patients; $P=0.044)$ but had a similar delay for adequate analgesia in the PACU $(32 \pm 9$ min vs $54 \pm$ 9 min for other patients; $P=0.14$ ). The mean RR at the end of the peroperative titration was not correlated to the quality of postoperative analgesia evaluated either by the delay of adequate analgesia or the amount of morphine necessary for pain control in the PACU. However, the importance of RR decrease was correlated to a reduced morphine amount in the PACU $\left(\mathrm{r}^{2}=0.24, P=0.035\right)$ (Figure) although not correlated to a reduced delay for adequate analgesia PACU $\left(\mathrm{r}^{2}=0.11, P=0.16\right)$. The dose of peroperative morphine titration was correlated to the decrease in peroperative $\mathrm{RR}\left(\mathrm{r}^{2}=0.24 ; P=0.03\right)$ but not correlated to reduced adequate analgesia delay $\left(\mathrm{r}^{2}=0.003\right.$; $P=0.83)$ or morphine dose needed in the PACU $\left(\mathrm{r}^{2}\right.$ $=0.06 ; P=0.30)$.

\section{Postoperative pain management}

The data are listed in Table II. The duration of the postoperative morphine titration was less in the Perop group than in the Postop group. The delay for adequate analgesia was less in the Perop than in the Postop group. Analgesia in the PACU required larger
TABLE II Analgesia in the Post Anesthesia Care Unit

\begin{tabular}{llll}
\hline & $\begin{array}{l}\text { Perop group } \\
(n=20)\end{array}$ & $\begin{array}{l}\text { Postop group } \\
(n=20)\end{array}$ & $P$ \\
\hline $\begin{array}{l}\text { Duration of PACU } \\
\text { titration (min) }\end{array}$ & $\begin{array}{l}29 \pm 5 \\
(0-75)\end{array}$ & $\begin{array}{l}49 \pm 4.5 \\
(10-90)\end{array}$ & 0.01 \\
$\begin{array}{l}\text { Delay for adequate } \\
\text { analgesia (min) }\end{array}$ & $\begin{array}{l}42 \pm 7 \\
(0-95)\end{array}$ & $\begin{array}{l}76 \pm 7 \\
(35-150)\end{array}$ & 0.0026 \\
$\begin{array}{l}\text { Morphine doses in the } \\
\text { PACU (mg) }\end{array}$ & $\begin{array}{l}7.25 \pm 1.3 \\
(0-20)\end{array}$ & $\begin{array}{l}15.4 \pm 1.5 \\
(3-28)\end{array}$ & 0.0004 \\
$\begin{array}{l}\text { Cumulative doses of } \\
\text { morphine } \\
\text { (per and post op) (mg) }\end{array}$ & $\begin{array}{l}17.5 \pm 1.6 \\
(9-29)\end{array}$ & $\begin{array}{l}15.4 \pm 1.5 \\
(3-28)\end{array}$ & 0.44 \\
$\begin{array}{l}\text { Duration of stay in the } \\
\text { PACU (min) }\end{array}$ & $\begin{array}{l}154 \pm 13 \\
(60-245)\end{array}$ & $\begin{array}{l}168 \pm 14 \\
(90-360)\end{array}$ & 0.59 \\
$\begin{array}{l}\text { Cumulative doses of } \\
\text { morphine } \\
\text { (24 hr) (mg) }\end{array}$ & $\begin{array}{l}31.2 \pm 3.7 \\
(15-69)\end{array}$ & $\begin{array}{l}29.3 \pm 4.5 \\
(1-64)\end{array}$ & 0.75 \\
\hline
\end{tabular}

Values are expressed as mean \pm SEM (range) or number of patients $(\mathrm{n})$

PACU: Post Anesthesia care Unit

Perop group: patients who received morphine at the end of surgery; Postop group: patients who did not receive morphine at the end of surgery but usual titration in the Post Anesthesia Care Unit.

TABLE III Side effects

\begin{tabular}{llll}
\hline & $\begin{array}{l}\text { Perop group } \\
(n=20)\end{array}$ & $\begin{array}{l}\text { Postop group } \\
(n=20)\end{array}$ & $P$ \\
\hline $\begin{array}{l}\text { Nausea, vomiting }(\mathrm{n}) \\
\text { Respiratory depression }(\mathrm{n})\end{array}$ & 2 & 3 & 0.67 \\
$\begin{array}{l}\text { Failure of postoperative } \\
\text { titration }(\mathrm{n})\end{array}$ & 0 & 5 & 0.017 \\
\hline
\end{tabular}

Values are expressed as number of patients (n)

Perop group: patients who received morphine at the end of surgery; Postop group: patients who did not receive morphine at the end of surgery but usual titration in the Post Anesthesia Care Unit.

doses of morphine in the Postop group than in the Perop group. However, the total amount of morphine, peroperative and postoperative, was similar in the two groups. The duration of stay in the PACU was similar in both groups. The amount of PCA morphine consumption was similar at $24 \mathrm{hr}$.

Side effects are listed in Table III. A similar number of patients developed nausea or vomiting in the PACU. The frequency of respiratory depression in the PACU was more frequent in the Postop than in the Perop 
group. Respiratory depression occurred in the PACU in five patients in the Postop group. In three cases, the respiratory depression occurred during the morphine titration which was interrupted after doses of $11 \mathrm{mg}, 15 \mathrm{mg}$ and $20 \mathrm{mg}$ respectively. In the fourth case, respiratory depression occurred five minutes after the end of a successful morphine titration using $27 \mathrm{mg}$ morphine. In the last case, respiratory depression occurred one hour after an unsuccessful morphine titration using $20 \mathrm{mg}$ morphine which was augmented by administration of propacetamol and ketoprofen $i v$. All these patients were monitored in the PACU and recovered without administration of naloxone.

Two patients in each group had failure of postoperative titration with no decrease in pain score (VAS pain score $\geq 50 \mathrm{~mm}$ after one hour of morphine). In these patients, VAS pain score was still high (50-70 $\mathrm{mm}$ ) $60 \mathrm{~min}$ after the start of morphine titration using $21 \mathrm{mg}$ morphine. Thus, there were five failures of titration in the Postop group (three respiratory depression, two persistent high pain score) compared with two failures in the Perop group (two persistent high pain score) ( $P$ : NS).

The management of pain was considered as very easy to easy for 15 patients in the Perop group $v s$ nine patients in the Postop group ( $P$ : NS). Patient evaluation of pain control showed good to excellent pain control in 13 patients in the Perop group vs eight patients in the Postop group $(P: N S)$ and side effects for eight patients in the Perop group $v s$ ten patients in the Postop group ( $P: \mathrm{NS})$.

\section{Discussion}

In this study peroperative morphine titration reduced the delay in achieving postoperative analgesia and the incidence of respiratory depression. The respiratory rate decrease during peroperative titration was correlated with the reduced need in postoperative morphine in the PACU.

This study is the first to suggest that peroperative morphine titration can facilitate postoperative pain management both in the quality of pain control and reduction of respiratory depression. Peroperative administration of a single morphine bolus as part of clinical practice has been suggested by some studies describing this technique, ${ }^{1-4}$ but the realization of peroperative morphine titration using repeated morphine boluses is rarely described, ${ }^{6}$ and has not been validated. The doses of peroperative morphine bolus previously evaluated varied between 0.15 and $0.25 \mathrm{mg} \cdot \mathrm{kg}^{-1} 20$ to $30 \mathrm{~min}$ before the end of surgery. ${ }^{1-4}$ In our study, the mean total dose of morphine titrated in anesthetized patients was close to $0.15 \mathrm{mg} \cdot \mathrm{kg}^{-1}$.
Previous studies have suggested that peroperative administration of a single bolus of morphine (0.1 $\left.\mathrm{mg} \cdot \mathrm{kg}^{-1}\right)$ did not modify the awakening concentration of isoflurane or sevoflurane. ${ }^{7,8}$ Similarly, in this study, extubation of the trachea was possible in all patients in the Perop group although no precise criteria for extubation were used. However, the range of the duration of peroperative titration $(10-55 \mathrm{~min})$ suggests that this titration may have delayed extubation in some patient. Our data show that the delay before adequate analgesia was achieved in the PACU can be reduced by $45 \%$ with peroperative titration. Peroperative morphine titration does not preclude morphine administration to complete analgesia in the PACU. The more intense analgesia obtained in the Perop group cannot be totally explained by an increase in total amount of morphine given which was not different between the groups. This more rapid analgesia in the PACU may be due to a shift in the timing to analgesia in the Perop group. In addition to the more rapid adequate analgesia, the patients of the Perop group had no incidence of respiratory depression as compared with five cases in the Postop group. The higher morphine dose used in the PACU in the Postop group may explain this higher incidence of respiratory depression. These cases of respiratory depression in the Postop group did not require naloxone antagonism or mechanical ventilation. This is probably related to the criteria used in our study to define respiratory depression which allowed detection of early signs of opioid overdosage. Other authors have observed that a peroperative bolus of $0.25 \mathrm{mg} \cdot \mathrm{kg}^{-1}$ morphine enhances analgesia after remifentanil-based anesthesia but is responsible for severe delayed postoperative respiratory depression requiring antagonization or ventilation. ${ }^{2}$ Our peroperative titration may have limited the incidence of respiratory depression by adapting the dose of opioid to the interindividual variability. ${ }^{5}$

What is the validity of the respiratory rate (RR) as a criterion of adequate peroperative morphine titration? The target of a respiratory rate of $12 \mathrm{bpm}$ initially chosen does not seem easy to reach. A slight majority of patient reached that target. These patients had good pain control according to the important reduction of the delay of analgesia and morphine need in the PACU. The RR at the beginning of peroperative titration varies among patients. The RR decrease during peroperative titration seems correlated to the quality of postoperative analgesia as reflected by the parallel reduced amount of morphine needed in the PACU to complete analgesia although this is not confirmed by a correlation with a shorter delay for adequate analgesia. However, although the dose of peroperative titrated morphine 
was correlated to the degree of peroperative $R R$ decrease, this dose of morphine was not correlated to the delay for adequate analgesia and the dose of morphine needed in the PACU. Therefore, the RR decrease during administration of peroperative titrated morphine may be helpful both for safety (i.e. no reduction of RR beyond $12 \mathrm{bpm}$ ) and quality of analgesia (degree of RR decrease). However this weak correlation $\left(\mathrm{r}^{2}\right.$ of 0.24$)$ means that only a partial prediction of postoperative morphine needs in the PACU by the peroperative RR decrease.

In conclusion, the peroperative administration of morphine titrated according to $\mathrm{RR}$ reduction in patients emerging from anesthesia can enhance the immediate postoperative analgesia, limit the incidence of respiratory depression and facilitate the management of pain in the PACU.

\section{References}

1 Yarmush J, D'Angelo R, Kirkhart B, et al. A comparison of remifentanil and morphine sulfate for acute postoperative analgesia after total intravenous anesthesia with remifentanil and propofol. Anesthesiology 1997; 87: 235-43.

2 Chauvin M, Lejus C, Scherpereel P, Cheli-Muller L, Hédonin M. Control of immediate postoperative pain in patients who received remifentanil during balanced anaesthesia for severely painful surgery. $\mathrm{Br} \mathrm{J}$ Anaesth 1998; 80(Suppl1): A613.

3 Sneyd JR Morphine before the termination of remifentanil provides effective transition to routine analgesia after major surgery: a comparison with current practice. Br J Anaesth 1998; 80(Suppll): A614.

4 Coetzee JF, van Loggerenberg $H$. Tramadol or morphine administered during operation: a study of immediate postoperative effects after abdominal hysterectomy. $\mathrm{Br}$ J Anaesth 1998; 81: 737-41.

5 Gourlay GK, Kowalski SR, Plummer JL, Cousins MJ, Armstrong PJ. Fentanyl blood concentration - analgesic response relationship in the treatment of postoperative pain. Anesth Analg 1988; 67: 329-37.

6 Christopherson R, Beattie C, Frank SM, et al. Perioperative morbidity in patients randomized to epidural or general anesthesia for lower extremity vascular surgery. Anesthesiology 1993; 79: 422-34.

7 Gross JB, Alexander CM. Awakening concentrations of isoflurane are not affected by analgesic doses of morphine. Anesth Analg 1988; 67: 27-30.

8 Katoh T, Suguro Y, Kimura T, Ikeda K Morphine does not affect the awakening concentration of sevoflurane. Can J Anaesth 1993; 40: 825-8. 